\title{
Los dating apps para varones: desafíos para el campo investigativo en Latinoamérica
}

\author{
Social research in dating apps for men: challenges to strengthen \\ the research field in Latin America
}

Rodrigo Lara Quinteros*

\begin{abstract}
Resumen
El presente artículo propone una reflexión en el campo de investigación social en torno a dating apps (aplicaciones de ligue) para varones y su vinculación con la sexualidad, en un escenario donde han primado enfoques biomedicalizantes. Desde ese lugar, se identifican dos tensiones importantes a desarrollar: el contexto sociocultural donde se inserta la investigación, y la posición del sujeto asumida teóricamente, implicando a su vez consideraciones epistémicas y ético-políticas. Se puntualiza la relevancia de incorporar de forma crítica y situada al contexto como encuadre y al sujeto como un ente activo. Se concluye con una discusión respecto a estos tópicos en el escenario latinoamericano, considerando su posición en el campo de circulación de conocimientos global.
\end{abstract}

Palabras claves: Investigación social, dating apps, varones, contexto sociocultural, no heterosexual.

\begin{abstract}
This article proposes a reflection on the field of social research around dating apps for men and their link with sexuality, in a setting where biomedicalizing approaches have prevailed. From that place, two important tensions to develop are identified: the sociocultural context where the research is inserted, and the position of the subject assumed theoretically, implying in turn epistemic and ethical-political considerations. The relevance of incorporating critically and situated in the context as a frame and the subject as an active entity is pointed out. The article concludes with a discussion regarding these topics in the Latin American scenario, considering their position in the field of global knowledge circulation.
\end{abstract}

Key words: Social research, dating apps, men, sociocultural context, non-heterosexual.

* Psicólogo, Magíster en Estudios de Género y Cultura, Mención Ciencias Sociales, Universidad de Chile. Doctor (c) en Psicología por la Universidad Diego Portales, Chile. Correo: rodrigo.lara.quinteros@gmail.com 
Revista Punto Género N ․ำ 13. Junio de 2020

ISSN 0719-0417 / 66 - 78

Fecha de recepción: Mayo 2020

Fecha de aprobación: Junio 2020

\section{Introducción.}

"Posiblemente los aportes latinoamericanos de más enjundia e impacto social puedan encontrarse allá donde la Psicología se ha dado de la mano con otras áreas de las ciencias sociales" (Ignacio Martín-Baró)

La ideología heteronormativa constituye un eje de análisis fundamental a la hora de problematizar las prácticas erótico-afectivas de varones que buscan vínculos con otros varones. Esta ideología posee gran fuerza en la esfera social y cotidiana, lo que se materializa en el supuesto de sentido común de que todas las personas son heterosexuales, y sus relaciones afectivas, románticas y sexuales también deben serlo (Serrato y Balbuena, 2015).Desde una óptica sociocrítica, estas ideologías e instituciones otorgan marcos restringidos para comprender las prácticas afectivas y sexuales que no se encuentran enmarcadas en ese encuadre como, por ejemplo, las prácticas homoeróticas.

En el caso de varones no heterosexuales o varones que buscan vínculos homoeróticos con otros varones, la relación entre la vivencia de su sexualidad y la utilización de dispositivos tecnológicos posee una larga data (Grov, Breslow, Newcomb, Rosenberg, Bauermeister, 2014). Miskolci (2015) señala que, en gran medida, estos usos tecnológicos por parte de varones no heterosexuales guardan relación con las condiciones de posibilidad social y cultural, comúnmente teñidas por lecturas estigmatizantes a nivel macro y microsocial.

En la última década, las dating apps (o aplicaciones de ligue) han emergido y se han consolidado como un espacio clave de interacción para varones no heterosexuales, dando lugar a un nuevo escenario donde los sujetos han ido reconfigurando sus subjetividades y sus prácticas eróticas y afectivas (Race, 2014; Ahlm, 2017; Fitzpatrick \& Birnholtz, 2017) en relación a los encuadres particulares que estas ofrecen. Sin embargo, una de las principales tensiones asociadas a estas prácticas guarda relación con las lecturas heteronormativas que las interpretan desde la degradación moral y la pérdida de los (supuestos) valores amorosos o afectivos que imperan en nuestra sociedad (McGlotten, 2013).

Con respecto a la relación entre tecnología y prácticas erótico-afectivas, McGlotten (2013) sostiene que vivimos en una sociedad que es al mismo tiempo tecnofílica y tecnofóbica, en tanto, si bien el uso de las tecnologías es relevado socialmente como algo placentero y necesario, simultáneamente las relaciones que se tejen ahí son sujetas a estigmas que las sindican como superficiales o de menor valor que las generadas en la presencialidad. 
Estos sesgos y estigmas también impregnan el campo científico, especialmente al considerar que la ciencia, en tanto régimen político, privilegia conocimientos androcéntricos y heteropatriarcales, es decir, desde la óptica de varones adultos, blancos, con privilegios de clase y heterosexuales (Maffia, 2014). De este modo, surge la alerta respecto al potencial estigmatizador y reduccionista que pueden alcanzar ciertas propuestas investigativas, especialmente al trabajar con grupos históricamente marginados (Teo, 2008).

El desarrollo investigativo en materia de dating apps y varones no heterosexuales ha puesto su foco en el ámbito de la salud sexual y en particular, en lo que respecta a las conductas de riesgo de transmisión del VIH y otras infecciones de transmisión sexual y su prevención. Esta operación implica la omisión del contexto donde se insertan dichas prácticas, y las narrativas y sentidos de quienes las protagonizan. Así, es posible visualizar el establecimiento de esencializaciones identitarias en torno a los "sujetos de riesgo", de la mano con un juicio respecto a las culturas digitales como espacios inherentemente riesgosos, limitando las posibilidades de comprensión y significación del fenómeno (Albury\& Byron, 2016).

En esta línea, el surgimiento y consolidación de las dating apps para varones plantea preguntas políticas relevantes en torno a los regímenes de visibilidad y reconocimiento de los sujetos y prácticas homoeróticas, en tanto dicha apertura de espacios podría guardar relación más bien con la operatoria neoliberal de trasformación de deseos y necesidades humanas en empresas rentables (Brown, 2015) más que como una consecuencia de la visibilización y apertura hacia otras subjetividades y prácticas no inscritas en la matriz heterocentrada.

Illouz (2007) plantea que, en el contexto actual, y dada la proliferación de experiencias románticas propiciada por el capitalismo, cuesta diferenciar experiencias erótico-afectivas de experiencias de consumo. Por esto, la racionalidad neoliberal también podría vincularse a los modos en que los sujetos configuran sus espacios de autopresentación para, de alguna forma, "invertir" en un mercado de capitales eróticoafectivos.

Desde el campo de lo social, la investigación respecto a las dating apps se ha desarrollado de forma exploratoria e incipiente desde el año 2014, y ha experimentado una tendencia al alza en los últimos cinco años. Respecto a los contextos donde se ha desarrollado dicha producción científica, es posible identificar un mayor desarrollo de estudios en contextos angloparlantes como Estados Unidos, Australia y diversos países de Europa, en contraste con una mucho menor producción en contextos latinoamericanos.

Dentro de los objetivos planteados por dichas investigaciones, se visualizan varias áreas de interés: experiencias y vivencias en torno a la sexualidad y a la intimidad (e.g. Race, 2014; Chan, 2018; Hobbs, Owen \& Gerber, 2016); elementos relacionales, negociaciones y usos de las dating apps, así como también oportunidades y riesgos identificados en dicho uso (e.g. Alburyet al, 2016; Macagapal et al., 2016; McKie, Milhausen \& Lachowsky, 2016); aspectos asociados a la producción e intercambio de imágenes de usuarios (e.g. Enguix \& Gómez-Narváez, 2017); aspectos espaciales o 
temporales del uso de dating apps (e.g. Blackwell, Birnholtz\& Abbott, 2014; Yeo \&Fung, 2017); configuración de los perfiles y los discursos de autopresentación (e.g. Grohmann, 2016), y aspectos asociados al uso y configuración de elementos lingüísticos en las dating apps (e.g. Miller et al, 2016).

En virtud de este campo de investigación emergente, el presente artículo tiene por propósito reflexionar en torno a los desafíos que subyacen al desarrollo de investigación científica de corte social, en relación con los usos de dating apps para varones no heterosexuales, proyectado en el escenario latinoamericano. Para ello, se presentará una contextualización general del surgimiento y proliferación de las dating apps para varones, junto con algunas líneas de estudio social que se han desarrollado progresivamente respecto al problema. Posteriormente, el análisis se enfocará en dos aspectos que son de amplia relevancia para reflexionar en torno a las implicancias epistemológicas y éticopolíticas de las investigaciones en este escenario: el contexto sociocultural y el lugar del sujeto en la investigación.

\section{Contexto general: Dating apps para varones}

Durante las últimas décadas, el internet y las nuevas tecnologías de la información y comunicación (TIC) se han ido masificando exponencialmente, tanto en sus posibilidades de acceso como de utilización y consumo. Los cambios tecnológicos, de la mano de la creación y proliferación de dispositivos que permiten el acceso y uso de internet fuera de espacios estáticos, como las tablets y especialmente los teléfonos móviles, han contribuido a la complejización progresiva de los usos y las posibilidades asociadas a las tecnologías digitales. En esta línea, Beleli (2015) sostiene que el internet ha permitido la creación de canales de comunicación de mayor horizontalidad, cuyo crecimiento se ha acelerado aún más con aplicaciones digitales móviles, en tanto estas combinan conectividad con movilidad.

La noción de tecnología afectiva reconoce los significados afectivos de las comunicaciones e intercambios que ellos median, a la par de también contribuir a modificar las formas en que las emociones son expresadas (Lasén, 2014; Rodríguez y Rodríguez, 2016); así, la presencia de los dispositivos móviles y sus propiedades en la vida cotidiana contribuiría a expresar emociones, pero también a controlarlas.

Un ejemplo de ello son los teléfonos móviles, respecto a los cuales Amparo Lasén (2014) plantea que estos se han transformado en tecnologías con las cuales los usuarios generan una relación de carácter afectiva tanto por la cercanía corporal que el dispositivo posee con el sujeto sostenidamente, como por la naturaleza inherentemente afectiva de la comunicación que propician.

En consonancia a su vinculación con lo afectivo y sexual, Internet ha provisto de distintas plataformas destinadas a transformarse en una instancia en la que las personas pueden buscar una amplia gama de vínculos. Un importante número de estos espacios digitales se encuentra dirigido a hombres gay y bisexuales, o bien a hombres que buscan 
interactuar en un medio homoerótico sin necesariamente sujetarse a una identidad no heterosexual.

Las dating apps para varones pueden entenderse como "tecnoespacios de bolsillo" que correlacionan con otros sitios que históricamente han estado diseñados para encuentros sexuales y afectivos entre hombres. Por lo mismo, sus características de diseño solo pueden ser entendidas realmente en referencia a infraestructuras y ambientes que han moldeado las prácticas sexuales y los deseos de los varones no heterosexuales históricamente (Albury et al, 2016).

Handel y Shklovski (2012) señalan que la característica central de las dating apps es su capacidad de localizar a los sujetos en tiempo real mediante el sistema GPS, lo que facilita los encuentros sociales y sexuales de forma mucho más localizada e inmediata, a diferencia de los sitios web de dating clásico, donde en general se requería un tiempo prolongado de comunicación online antes del encuentro en persona.

En las dating apps los usuarios se vuelven visibles a la comunidad en virtud de su proximidad geográfica, lo que constituye una profunda ampliación del repertorio de posibilidades erótico-afectivas, principalmente en lo relativo a la inmediatez de las interacciones posibles de gestar (Blackwell et al, 2014). En esta línea, Miller (2015) identificó siete ganancias o gratificaciones que hombres homobisexuales obtienen por usar dating apps: seguridad (asegurarse que todas las personas participantes son elegibles), control (determinar con quién interactuar y con quién no), facilidad de uso, accesibilidad (acceder a un amplio número de varones), movilidad (identificar varones cercanos en ubicación), conectividad (construye cierto sentido de comunidad) y versatilidad (plausibilidad de múltiples usos).

Por otro lado, también se han identificado diversas tensiones relacionadas al uso de dating apps, principalmente asociadas a la tergiversación de información personal y social, a la difusión no deseada de imágenes o diálogos de carácter privado y además la posibilidad de un feedback "poco exitoso", es decir, que no logra vínculos, pudiendo añadir nuevas angustias y malestares subjetivos (Corriero et al, 2016, Tziallas, 2015, McGlotten, 2013).

Race (2014) señala que un punto central respecto a la utilización de las aplicaciones de dating gay radica en cómo estas participan en la emergencia de nuevas prácticas sexuales, nuevas vinculaciones y nuevas distribuciones de la intimidad. Asimismo, el autor señala que estas aplicaciones y su capacidad de develar oportunidades sexuales y sociales que se encuentran próximas en distancia, producen una experiencia novedosa en cuanto al espacio social en donde se desarrollan las interacciones y potenciales encuentros.

\section{Implicancias para la investigación social}

Como se señaló anteriormente, el campo de investigación de las sexualidades en el contexto de la tecnologización de la vida cotidiana, y en particular, aquellas estigmatizadas por los cánones heteronormativos es de relativa novedad y, por lo mismo, 
la construcción del conocimiento ha sido principalmente de carácter exploratoria y llevada a cabo en contextos angloparlantes que ostentan, desde un punto de vista geopolítico, la hegemonía del conocimiento. Esto posee implicancias epistemológicas y ético-políticas que son indispensables de revisar para proyectar este campo de investigación en el territorio latinoamericano de forma relevante y rigurosa. Por esto, se han seleccionado dos grandes dimensiones que evidencian las implicancias antes mencionadas: el contexto sociocultural y el lugar que se le otorga al sujeto en la investigación

\section{Contexto sociocultural como brújula política}

Discutir la noción de contexto sociocultural requiere dos vertientes de análisis, si bien no excluyentes, necesarias de puntualizar: la disciplinar y la empírica. En cuanto al contexto sociocultural desde lo disciplinar, lan Parker (2010) sostiene que la psicología se vincula con el modelo político-económico dominante, es decir, el capitalismo neoliberal.

Si extrapolamos este análisis a otros lugares políticos de enunciación, podríamos plantear que también existe una ligazón entre la psicología como disciplina, y el pensamiento heterosexual como un régimen político que lee expresiones, subjetividades, prácticas y símbolos desde lógicas y códigos heterosexuales (Wittig, 2016). Esto sería coherente con el planteamiento de Parker (2010) entorno a la psicología como una ideología cristalizada que posee estrechos horizontes, desde los cuales también moldea a los sujetos que participan en investigaciones, muchas veces sosteniendo y legitimando los estigmas que se han configurado socioculturalmente en torno a varones ( $y$ otras subjetividades) no heterosexuales.

La pretensión de la psicología por hallar procesos de carácter universal, que permitan desarrollar explicaciones estandarizadas al comportamiento humano desde lógicas causa-efecto y que, además, trasciendan la impronta cultural de los sujetos (Parker, 2010), supone una falacia que no solamente tiene implicancias disciplinares asociadas a generar corpus de saber epistemológicamente reduccionistas y políticamente peligrosos, sino que, además, posee implicancias encarnadas directamente en el campo empírico, o en el campo del "conocimiento posible".

Al mismo tiempo, resulta fundamental problematizar el lugar ético y epistémico desde el cual las Ciencias Sociales han ido tejiendo saberes respecto a los grupos de personas no heterosexuales. Como se señaló anteriormente, gran parte de la investigación científica con varones no heterosexuales y su uso de dating apps se encuentra asociada en sus orígenes a la relación entre estos sujetos y la prevalencia de infecciones de transmisión sexual. Frente a esto, surge la pregunta en torno al por qué estas problemáticas - y no otras - son las que se piensan más relevantes de responder científicamente cuando se habla de la sexualidad de varones no heterosexuales, lo que implica desarrollar un análisis desde el contexto de descubrimiento para dar cuenta del porqué del interés investigativo de los autores sobre estas materias y no otras (Teo, 2008). 
La consideración de variables sin contexto da lugar a resultados equívocos o problemáticos éticamente hablando. En este sentido, el ignorar el régimen de invisibilidad y las dificultades en el acceso a una sexualidad no sancionada culturalmente genera lecturas de los fenómenos que se encuentran siempre supeditadas a los límites que la heteronormatividad ofrece.

El escenario del trabajo empírico actual, donde las investigaciones sociales de mayor divulgación se han concentrado en territorios específicos, si bien sirve de "hoja de ruta" para pensar algunas claves del problema de las dating apps, también supone el riesgo de la generalización de ese conocimiento. McGuire (2016) buscó conocer la experiencia de uso de dating apps homoeróticas en Seúl (Corea del Sur). Este contexto es caracterizado por el autor como un lugar donde lo digital se encuentra sujeto a una enorme vulnerabilidad dado que los contenidos del internet tienden a ser viralizados, es decir, expuestos de forma rápida y repentina a grandes porciones de la población, a la par de un Estado surcoreano que es caracterizado como ampliamente vigilante de los contenidos del internet. Por otro lado, la impronta cultural local altamente confucionista privilegia la "doble vida" (o el matrimonio para encubrir) como modo de afrontamiento del deseo no heterosexual.

La investigación de McGuire (2016) arrojó resultados que, al ser contrastados con estudios realizados en contextos occidentales, reflejan una percepción de las dating apps como lugares altamente peligrosos debido a la posibilidad que experimentan los usuarios de ser "sacados del closet" de forma forzosa por otros usuarios. Este riesgo constituía el argumento central esgrimido por los participantes para preferir espacios públicos de cruising ${ }^{1}$ donde la interacción es desde un principio cara a cara. En síntesis, para el autor, las ansiedades sobre la conexión sexo tecnológica y la difuminación de las fronteras entre las diferentes áreas de la vida de los sujetos son las principales características de la experiencia queer contemporánea en Corea del Sur (McGuire, 2016).

Estos resultados se oponen al saber común, que emerge en un número amplio de estudios, en torno a las dating apps como un espacio que, si bien representa tensiones, también ha desplazado en participación a los otros lugares coexistentes en lo que podría denominarse la "arquitectura urbana gay". El contexto sociocultural en torno a lo homoerótico en Corea delimita y hace emerger otras posibilidades, alcances y vivencias en torno al uso de dating apps. Esto podría constituir una brújula política para leer lo homoerótico, dejando en evidencia la multiplicidad de significaciones excluidas a partir de generalizaciones que son coherentes con constructos como el de "cultura gay", ampliamente inscrito en lo social, siguiendo la misma línea.

\section{La posición del sujeto en la investigación.}

Esta segunda dimensión de análisis emana también desde la reflexión en torno al contexto sociocultural en tanto, como señala Parker (2010), la pretensión de universalidad

\footnotetext{
${ }^{1}$ Refiere a prácticas eróticas y sexuales que se llevan a cabo en espacios públicos de forma clandestina.
} 
tiene por consecuencia la desaparición de las voces de múltiples sujetos de investigación que pueden tomar otras direcciones distintas a las que producen las generalizaciones.

La posición del sujeto da cuenta de los intereses epistemológicos conscientes e inconscientes que subyacen a la investigación y, por lo mismo, abre un campo de tensión importante de discutir. Al respecto, un problema visualizado en las investigaciones sobre dating apps, desde un enfoque biomédico, radica en la omisión de las narrativas que los propios sujetos articulan en torno a su sexualidad, focalizándose más bien en prácticas de riesgos y prácticas preventivas de amplia extensión como, por ejemplo, el uso del condón.

En relación con ello, la emergencia de nuevos dispositivos digitales y sus estructuras materiales abre no solamente una serie de nuevas configuraciones en el ámbito de la sexualidad, sino que también en el plano de la investigación. Sin embargo, una tensión se presenta al intentar dar cuenta de estos nuevos escenarios eróticos desde el estudio de las dating apps, sin la consideración del papel que toma el sujeto en esa ecuación.

En palabras de Race (2014), es importante considerar que el encuadre tecnológico de las dating apps no posee una relación determinista con las prácticas erótico-afectivas que permite. Para comprender dichas prácticas es necesario tomar en cuenta las características, formatos, funciones y diseños de las dating apps, pues es la propia materialidad de los textos escritos y de las imágenes digitales, en parte, la que genera nuevas capacidades, experiencias y vectores afectivos.

Las dating apps para varones podrían ser leídas como un nuevo encuadre para la sexualidad que es vivida y significada por los sujetos. Pensar en las dating apps como actantes deterministas de las transformaciones de la sexualidad contemporánea es también borrar los posicionamientos de los sujetos, dejándolos en segundo plano y quitando toda posibilidad de comprensión localizada de dicho fenómeno, tanto en lo geográfico, como en el contexto de la propia biografía de los sujetos.

Un planteamiento sostenido desde la materialidad de las dating apps es que ahí se vive una supremacía de la imagen por sobre lo discursivo, aspecto que al mismo tiempo se ve restringido en posibilidades de expresión, dada la limitación de caracteres y espacio para ello (Lasén, 2014; Miskolci, 2015; Beleli, 2015). Así, en el campo del discurso de auto presentación por medio de perfiles, existen una serie de denominaciones predeterminadas que permiten a los usuarios describirse en función de características físicas (edad, altura, peso, complexión física), intereses (¿qué busca?, posición o rol sexual), origen étnico, situación amorosa y pertenencia a alguna marca cultural o tribu dentro de lo homosexual, además de un breve apartado donde, en un número reducido de caracteres, los usuarios pueden escribir libremente algo sobre ellos.

Dichas estructuras pueden resultar rígidas y limitadas si se las asume como las únicas posibilidades para dar cuenta de la multiplicidad de subjetividades y las prácticas que los sujetos desplieguen en el uso de las aplicaciones. La interpelación no está puesta en desconocer el marco que proveen los nuevos escenarios tecnológicos, sino en comprenderlos como parte de condiciones de posibilidad de emergencia, dentro de las cuales el sujeto también ha sido parte activa, lo que da cuenta que en la investigación 
social la vida de un sujeto y la historia de una sociedad no pueden entenderse sin la comprensión de ambos aspectos en relación (Wright Mills, 1986). En síntesis, lo virtual en tanto entrelazado en la vida cotidiana de los sujetos, no es suficiente por sí mismo para dar cuenta de los fenómenos culturales que pretende relevar la investigación social (McGuire, 2016).

\section{Discusiones: desafíos para la investigación social latinoamericana}

Para iniciar las discusiones y conclusiones, se retoma la idea que abre el texto, en la que Martín-Baró (1983) sostiene que los aportes latinoamericanos de mayor impacto social en el marco de la psicología se originan cuando esta se une con otras áreas de las Ciencias Sociales, implicando una colaboración y un aprendizaje mutuo más allá de las diferencias epistemológicas que puedan existir a la base. Asimismo, para Martín-Baró la concientización emerge desde la dialéctica de lo individual y lo colectivo o comunitario, constituyendo una respuesta histórica a la carencia de palabra personal y social de los pueblos latinoamericanos, no sólo imposibilitados para leer y escribir el alfabeto, sino sobre todo para leerse a sí mismos y para escribir su propia historia.

Estos planteamientos ponen un acento en el campo de la circulación de las ideas científicas y los lugares de autoridad y saber que se erigen en occidente, a partir de variables geopolíticas de sustentabilidad de planteles académicos, inyección de recursos para investigación, entre otras. Más allá de esta realidad, resulta fundamental visualizar las consecuencias que esto tiene sobre los sujetos: nuestra realidad es y ha sido leída e interpretada por otros con mayor capital simbólico; la autoridad está fuera.

Frente a esa panorámica, discutir la contextualidad y el lugar del sujeto son herramientas centrales para pensar en una investigación social latinoamericana en general y en particular en el campo de las dating apps para varones, que reviste sus propias complejidades. Al menos en Chile, los Informes Anuales de Derechos Humanos de la Diversidad Sexual y de Género en Chile $^{2}$ son claros en entregar una panorámica general: los casos de violencia basados en orientación sexual e identidad de género han experimentado una preocupante tendencia al alza, siendo el 2019 el año más violento para la población LGBTI en Chile, un aumento de un 58\% de denuncias por homolesbotransfobia (MOVILH, 2019) en un escenario político de fuerte disputa entre posiciones emancipatorias y neoconservadoras. Preguntarse cómo en este escenario las dating apps para varones se insertan y los significados que reviste para quienes las usan, es de vital importancia.

Latinoamérica vive un proceso de derechización política que trae consigo a la palestra, entre otras cosas, una mayor vitrina para discursos neoconservadores que se oponen a la igualación de derechos fundamentales de la diversidad sexual, legitimando directa o indirectamente la violencia cotidiana. En este sentido, resulta central vincular los

\footnotetext{
2 Documentos desarrollados de forma anual por el Movimiento de Liberación Homosexual (MOVILH), cuyo propósito es el de sistematizar información en torno a diversos ámbitos de las condiciones de vida y participación social de personas y grupos LGTBIQ+.
} 
diseños de investigación social con las realidades políticas y culturales del territorio, para aportar a que Latinoamérica pueda ser pensada desde Latinoamérica.

Sin ir más lejos, la preocupante alza de casos notificados de VIH en la población de varones homobisexuales acontecida en Chile el año 2017, no debiese ser entendida desde criterios homogeneizadores, sino que más bien, desde la aproximación a las narrativas que los sujetos realizan sobre sus prácticas sexuales y los sentidos que ahí se articulan. Una aproximación social desde las dating apps y su lugar en la vivencia del homoerotismo y la sexualidad podría aportar en ese y otros caminos, lo que releva a su vez la importancia de la colaboración interdisciplinaria para transitar hacia una comprensión más compleja del fenómeno.

Finalmente, se concluye que la posición geopolítica que ostenta Latinoamérica en materia de circulación de los saberes interpela a investigadores sociales a integrar los contextos socioculturales y a los sujetos como lugares indispensables en la producción de saberes. Leer las dating apps para varones como una tecnología idealizada o una tecnología determinista, es desconocer a los sujetos activos que están detrás de sus usos, creando significados de forma sostenida, y el desconocimiento de estos sujetos, especialmente en la posición social en que se encuentran, constituiría una práctica científica homofóbica y violenta.

\section{Bibliografía:}

Albury, K. \& Byron, P. (2016). Safe on My Phone? Same-Sex AttractedYoung People's Negotiations of Intimacy, Visibility, and Risk on Digital Hook-UpApps. Social Media + Society. Vol 2, N4, p. 1-10.

Ahlm, J. (2017). Respectable promiscuity:Digital cruising in an era of queer liberalism. Sexualities. Vol 20, №3, p. 364-379.

Beleli, I. (2015). The Imperative of Images: Construction ofAffinities through the Use of Digital Media. Cadernos Pagu. № 44, p.1-114

Blackwell, C., Birnholtz, J. \& Abbott, C. (2014). Seeing and being seen:Co-situation and impresión formation using Grindr, a location-aware gay dating app. New Media \& Society. Vol 17, No 7, p.1117- 1136

Brown, W. (2015). El pueblo sin atributos, la secreta revolución del neoliberalismo. Barcelona: Malpaso ediciones.

Chan, L. (2018). Ambivalence in networkedintimacy: Observations from gay men using mobile dating apps. New media \& Society. Vol 20, N 7, p. 2566-2581 
Corriero, E. \& Tong, S. (2016). Managing uncertainty inmobile dating applications:Goals, concerns of use, and information seeking in Grindr. Mobile Media \& Communication. Vol 4, N 1, p. $121-141$

Enguix, B. \& Gómez-Narváez, E. (2017). Masculine Bodies, Selfies,and the $(\mathrm{Re})$ configurationsof Intimacy. Men and Masculinities. Vol 21, № 1, p. 112 130.

Fitzpatrick, C. \& Birnholtz, J. (2017) “I Shut the Door": Interactions, tensions,and negotiations from a location-based social app. new media \& society. New Media \& Society. Vol 20, № 7, p. $2469-2488$

Grohmann, R. (2016). Nãosou/ não curto:sentidos circulantes nosdiscursos de apresentaçãodo aplicativo Grindr. Sessões do Imaginário. Vol 21, №35, p. 7079.

Grov, C., Breslow, A., Newcomb, M., Rosenberg, J. \& Bauermeister, J. (2014). Gay and Bisexual Men's Use of the Internet: Research from the 1990s through 2013. The Journal of Sex Research. Vol 51, N4, p. 390-409

Handel, M. and Shklovski, I. (2012) Disclosure, ambiguity \& risk reduction in real-time dating sites. In: Proceedings of the ACM conference on Group Work. p. 175178.

Hobbs, M., Owen, S. \& Gerber, L. (2016). Liquid love? Dating apps, sex,relationships and the digital transformation of intimacy. Journal of Sociology. Vol 53, $\mathrm{N}^{\circ} 2, \mathrm{p}$. 271-284

Illouz, E. (2007). Intimidades Congeladas: las emociones en el capitalismo. Buenos Aires: Katz Editores.

Lasén, A. (2014). Affective technologies - emotions and mobile phones. Receiver Magazine. Rescatado de www.receiver.vodafone.com

Maffia, D. (2014). Epistemología Feminista: La subversión semiótica de las mujeres en la ciencia. Revista Venezolana de Estudios de la Mujer, № 28

Macapagal, K., Coventry, R., Puckett, J., Phillips II, G \&Mustanski, B. (2016). Geosocial Networking App Use Among Men Who Have Sex with Men in Serious Romantic Relationships. Archives of Sexual Behavior. Vol 45, № 6, p. 15131524.

Martín-Baró, I. (1983). Acción e ideología. Psicología social desde Centroamérica. San Salvador: UCA Editores. 
Revista Punto Género N ․ 13. Junio de 2020

ISSN 0719-0417 / 66 - 78

McGlotten, S. (2013). Virtual Intimacies: media, affect and queer sociality. Nueva York: State University of New York Press

McGuire, M. (2016) The problem of technological integration and geosocial cruising in Seoul. New Media \& Society. Vol 20, p. 369 - 383

McKie, R. Milhausen, R. \&Lachowsky, N. (2016). "Hedge Your Bets": Technology's Role in Young Gay Men's Relationship Challenges. Journal of Homosexuality.Vol 64, No 1, p. $75-94$

Miller, B. \& Behm-Morawitz, E. (2016). "Masculine Guys Only": The effects of femmephobic mobile dating application profiles on partner selection for men who have sex with men. Computers in Human Behavior. Vol 62, p.176-185.

Miller, B. (2015). “Dude, where's your face?" Self-presentation, self-description,and partner preferences on a social networking application for men who have sex with men: A content analysis. Sexuality \& Culture. Vol 19, №4, p. 637-658

Miskolci, R. (2015). "Discreet and out of the gay scene", notes on contemporary sexual visibility. Cadernos Pagu, N 44, p. 61-90

Movimiento de Liberación Homosexual, MOVILH (2019). XVIII Informe Anual de Derechos Humanos: diversidad sexual y de género en Chile. Recuperado de http://www.movilh.cl/documentacion/Informe-DDHH-Movilh-2019.pdf

Parker, I. (2010). La psicología como ideología: Contra la disciplina. Barcelona: Catarata,

Race, K. (2014). Speculative pragmatism and intimate arrangements: online hook-up devices in gay life. Culture, health \& sexuality: Vol 17. $N^{\circ} 4$, p. 496-511

Rodríguez, Z. \& Rodríguez, T. (2016). Los jóvenes, la comunicación afectiva y las tecnologías: entre la ritualización de la expresión y la regulación emocional. Intersticios sociales №11, Universidad de Guadalajara.

Serrato, A., \& Balbuena R. (2015) Calladito y en la oscuridad. Heteronormatividad y clóset, los recursos de la biopolítica. Culturales. Vol 3, N², p.151-180

Teo, T. (2008). From speculation to epistemological violence: a critical-hermeneutic reconstruction. Theory \& Psychology. Vol 18, ํ1, p. 47-67.

Tziallas, E. (2015). Gamified Eroticism: Gay Male "Social Networking"Applications and Self-Pornography. Sexuality \& Culture. Vol 19, № 4, p. 759-775

Wittig, M. (2016). El Pensamiento Heterosexual y otros ensayos. España: EGALES 
Revista Punto Género N. 13. Junio de 2020

ISSN 0719-0417 / 66 - 78

Mills, Charles Wright, et al (1986). La imaginación sociológica. México: Fondo de Cultura Económica,

Yeo, T. \& Fung, T. (2017). "Mr. Right Now": Temporality of relationship formation on gay mobile dating apps. Mobile Media \& Communication. Vol 6, № 1, p. $3-18$ 